\title{
Accurate determination of the total hemispherical emittance and solar absorptance of opaque surfaces at elevated temperatures
}

\author{
Daniel Kraemer ${ }^{\mathrm{a}, *}$, Kenneth McEnaney ${ }^{\mathrm{a}}$, Feng $\mathrm{Cao}^{\mathrm{b}}$, Zhifeng Ren ${ }^{\mathrm{b}}$, Gang Chen ${ }^{\mathrm{a}}$ \\ ${ }^{a}$ Department of Mechanical Engineering, Massachusetts Institute of Technology, Cambridge, MA 02139, USA \\ ${ }^{b}$ Department of Physics and TcSUH, University of Houston, Houston, Texas 77204, USA.
}

\begin{abstract}
In many applications such as solar power conversion technologies, radiative heat transfer plays a significant role in the energy balance. For accurate performance predictions of solar power conversion devices the total hemispherical emittance and solar absorptance of surfaces need to be known with high accuracy. Often times the emittance of a surface is calculated from indirect spectral bidirectional or directional-hemispherical reflection measurements at room temperature which can significantly underestimate the total hemispherical emittance. Here, we report a simple steady-state calorimetric method to directly measure the total hemispherical emittance of opaque surfaces at elevated temperatures with a maximum experimental uncertainty of $5 \%$. The method is further expanded to directly measure the solar absorptance of the surface at elevated temperature using a solar simulator. We show experimental total hemispherical emittance and solar absoprtance results for various surfaces such as machine polished copper and stainless steel and several spectrally selective solar absorbers. We describe a methodology to characterize solar absorbers and apply it to a cermet-based spectrally selective solar absorber.
\end{abstract}

\section{Introduction}

Radiation is a relevant heat transfer mechanism in countless applications such as high temperature industrial processes, heat management in buildings, space applications, and solar power conversion [1-3]. The far-field radiated power from a blackbody is related to its temperature by the Stefan-Boltzmann law and is diffusely emitted in the form of electromagnetic waves with a temperature-dependent wavelength spectrum [4-6]. However, real materials typically radiate at a fraction of the blackbody's emissive power. This fraction is defined as the emissivity which typically is a function of the material's temperature and the wavelength and direction of the emitted electromagnetic waves [7]. Equivalently, the absorptivity is the optical material property that determines the fraction of irradiated power absorbed by a real surface relative to a blackbody. Whereas the emissivity and absorptivity are pure material properties, oftentimes those properties are affected by the condition and structure of the surface (oxide layer, surface roughness, subwavelength multilayer thin films) in which case one uses the terminology emittance and absorptance, respectively. The temperature, wavelength, and directional

\footnotetext{
${ }^{*}$ Corresponding author. Tel.: (617) 253-7488

E-mail address: dkraemer@mit.edu (D. Kraemer)
} 

have been developed each with their own ranges of applicability, advantages and shortcomings $[7,8]$. The techniques to measure the emittance can loosely be separated into three groups: reflection, radiometric emission, and calorimetric emission measurements.

With reflection measurement methods the emittance (absorptance) is obtained indirectly from the measured reflectance based on the relation for opaque materials, $\varepsilon=\alpha=1-\rho$ with $\varepsilon, \alpha$, and $\rho$ being the emittance, absorptance, and reflectance, respectively. However, this already leads to one of the main shortcomings of these techniques when used for low-emittance samples because a small relative error in the measured reflectance results inevitably in a significantly larger relative error in emittance [9]. Nevertheless, there are various absolute and relative techniques used to measure the spectral bidirectional, spectral directional-hemispherical or spectral hemispherical-directional reflectance using monochromatic or polychromatic light sources [2,7,10-15]. Here, we use the term "spectral" to refer to the reflectance or emittance at a single wavelength, as opposed to the term "total" which refers to the property averaged over a given spectrum (e.g. a blackbody spectrum at a given temperature, or the AM1.5G solar spectrum). Reflectance measurements are described by the angular distributions of first the incident spectrum, and then the measured reflection; for example, a directional-hemispherical measurement has a single-direction incident spectrum, but the reflection is the sum over all outgoing angles. To obtain the directional-hemispherical or hemispherical-directional reflectance the techniques are based on integrating sphere, integrating mirror or heated cavity reflectometers or they use a hemispherical diffuse light source [16-20]. Oftentimes, the measurements require a reference standard and are performed with the sample at room temperature and only for one angle, thus calculating the total hemispherical emittance for the sample at elevated temperature can result in significant errors.

In order to avoid the challenges of an indirect measurement, radiometric methods are used to directly measure the spectral directional emittance of opaque or partially transparent samples using a spectrometer by comparing their emission spectra to that of a blackbody reference [2126]. The experimental systems used for these techniques are typically quite complex; their three major challenges are measuring only the radiation emitted by the sample, ensuring sample temperature uniformity, and accurately measuring the sample temperature. Whereas steady-state radiometric methods need a reference and are limited to relatively high temperatures to minimize errors from ambient radiation reflecting off of the sample, periodic radiometric methods can eliminate this effect and the directional emittance can be directly calculated by comparing to a reference. By adding a simultaneously performed periodic hemispherical-directional reflection measurement the directional emittance can be obtained without a reference [27]. Instead of measuring the spectral directional emittance at several angles, radiometric techniques based on the Land Surface Pyrometer can directly measure the spectral hemispherical emittance [28,29]. However, those techniques have rather large uncertainties and if the total hemispherical emittance is of primary interest, calorimetric methods performed under vacuum are considered to 
have the highest measurement accuracies due to their direct and absolute nature [30]. These techniques can either be steady-state or transient with some of their main challenges being to minimize parasitic heat losses and to perform accurate temperature measurements [31]. In transient techniques the emittance is obtained by relating the cooling curve to the radiative heat loss, assuming that the heat capacity is known as a function of temperature [32-37]. Radiative or inductive heating of the sample is typically preferred over electrical heating. It is also common to coat the complete specimen with the sample material to minimize parasitic heat losses. For sample surfaces deposited on flat sheet metal substrates such as for solar selective coatings the parasitic heat losses from the back side and through the supports can be minimized with a rather complex heated radiation shield requiring sophisticated temperature control [38].

Steady-state techniques relate the radiative heat loss, and thus the total hemispherical emittance, directly to the electrical power input required to maintain a sample at a constant elevated temperature, thus eliminating the uncertainty from an additional heat capacity measurement. In this type of experiment the thermodynamic equilibrium between the system and its surroundings is of great importance because transients can introduce large measurement errors [31]. In some techniques the sample-heater assembly is suspended on pillars and while the sample surface faces a blackbody surrounding at constant lower temperature, the back side and supports are surrounded by a heated radiation shield at sample temperature to minimize parasitic heat losses [39-43]. Similarly, concentric vacuum tube configurations are used with the sample surface deposited on the outside of the inner tube and an electrical heater embedded on the inside. Guard heaters at the tube ends minimize the edge effects [44,45]. Other techniques sandwich a thin electrical heater between two samples and suspend the assembly inside a vacuum chamber. The main challenges of these methods are to establish a uniform sample temperature and to measure the temperature accurately while minimizing the edge and wire heat losses [46-48]. It is particularly challenging to minimize the edge and wire heat losses for samples with low emittance due to the finite thickness of the sample-heater assembly needed to ensure temperature uniformity.

Here we develop a simple steady-state calorimetric method that determines the total hemispherical emittance of flat opaque samples with a maximum error below $5 \%$ by calibrating for the aforementioned inevitable parasitic heat losses. We also introduce a technique to probe internal thermal resistances of the assembly in order to validate (1) the assumption of consistent parasitic heat losses in experimental runs; and (2) the accuracy of our sample temperature measurement which can be one of the main sources of errors in those methods [31]. To demonstrate the method we measured various samples including machine-polished copper, machine-polished stainless steel, and solar absorbers with spectrally selective surfaces deposited on copper and stainless steel substrates at steady-state set temperatures ranging from 100 $500{ }^{\circ} \mathrm{C}$. The method is further expanded to also measure the solar absorptance at elevated temperatures using a solar simulator [43]. The absorptance of a reference black paint (HE6) is measured at temperatures from $100-300{ }^{\circ} \mathrm{C}$ [49]. Finally, a methodology is proposed to characterize spectrally selective solar absorbers. 


\section{Measurement methods, theory, and systems}

The developed techniques are steady-state calorimetric methods in which the electrical input power can directly be related to the total hemispherical emittance or the solar absorptance of a sample surface at elevated temperatures. The methods are based on particular forms of the more general heat balance expression for a sample suspended in an evacuated blackbody surrounding,

$$
C \frac{\partial T}{\partial t}=-A_{s} \varepsilon_{s}\left(T_{s}\right) \sigma T_{s}^{4}+A_{s} \int_{0}^{\infty} \alpha_{s, \lambda}\left(T_{s}\right) E_{b, \lambda}\left(T_{a m b}\right) d \lambda+\alpha_{s, s o l} Q_{s o l}+P_{H}-Q_{p}
$$

where the left-hand side is the unsteady term with $\mathrm{C}$ being the heat capacitance of the system, and $\partial \mathrm{T} / \partial \mathrm{t}$ the change in temperature with time which is zero when the system reaches a steady state. The first term on the right-hand side corresponds to the emitted radiation from the sample surface at temperature $T_{s}$ with area, $A_{s}$, total hemispherical emittance, $\varepsilon_{s}$, and $\sigma$ being the StefanBoltzmann constant. The second term is the irradiance from the blackbody surrounding absorbed by the sample surface. It is expressed in terms of the wavelength integral of the spectral hemispherical absorptance, $\alpha_{\mathrm{s}, \lambda}$, of the sample at $\mathrm{T}_{\mathrm{s}}$ multiplied by the spectral blackbody emissive power, $E_{b, \lambda}$, of the surrounding at temperature $T_{a m b}$. This will take into account the effect of non-gray properties of a sample. The third term accounts for possible incident solar radiation power, $\mathrm{Q}_{\text {sol }}$ being absorbed by the sample surface with the solar spectrum weighted absorptance, $\alpha_{\mathrm{s}, \mathrm{sol}}$. Furthermore, an electrical heater power input, $\mathrm{P}_{\mathrm{H}}$, balances the net heat flow from the sample surface and the parasitic heat losses, $Q_{P}$ which includes wire heat conduction as well as possible back side and edge radiation.

\subsection{Total hemispherical emittance measurement technique}

Whereas typical steady-state calorimetric techniques try to minimize the parasitic heat losses, the method developed here calibrates for those heat losses by performing three consecutive measurements (Fig. 1). The method requires two similar heater assemblies (1 and 2) to which two identical samples (1 and 2) are attached. For the first two experiments (subscripts 1 and 2) the sample-heater assemblies 1 and 2 are consecutively suspended in a large vacuum chamber acting as a blackbody surrounding at uniform temperature, $\mathrm{T}_{\mathrm{amb}}$. In each measurement, the required electrical power input, $\mathrm{P}_{\mathrm{H}}$, to balance the sample-heater assembly heat losses is measured for various steady state set temperatures, $\mathrm{T}$. The heat losses include the radiation from the sample, $\mathrm{Q}_{\mathrm{s}}$, and the parasitic heat losses, $\mathrm{Q}_{\mathrm{p}}$. The latter consist of the wire heat conduction from I/V leads, $\mathrm{Q}_{\mathrm{L}}$, and from thermocouples, $\mathrm{Q}_{\mathrm{TC}}$, as well as the back side and edge radiation, $\mathrm{Q}_{\mathrm{B}}$. Both experiments 1 and 2 are performed similarly with the only difference that the sample surfaces face in the opposite directions. For the third (parasitic heat loss calibration) experiment the two sample-heater assemblies are attached to each other on their sample surfaces eliminating their surface heat losses, $\mathrm{Q}_{\mathrm{S} 1}$ and $\mathrm{Q}_{\mathrm{S} 2}$. The required electrical heater power input, $\mathrm{P}_{\mathrm{HC}}$, is measured to reach the same steady state set temperatures as in the previous two measurements, and therefore corresponds to the above described parasitic heat losses of the two sample-heater 
assemblies. Consequently, the heat loss from the two identical sample surfaces and with that the total hemispherical emittance, $\varepsilon_{s}$, can be related to the measured electrical heater power inputs, $\mathrm{P}_{\mathrm{H} 1}, \mathrm{P}_{\mathrm{H} 2}, \mathrm{P}_{\mathrm{HC}}$ and the measured sample and ambient temperatures, $\mathrm{T}_{\mathrm{s}}$ and $\mathrm{T}_{\mathrm{amb}}$ with

$$
\varepsilon_{S}\left(T_{s}\right)=\frac{P_{H 1}+P_{H 2}-P_{H C}}{2 A_{s} \sigma\left(T_{s}{ }^{4}-T_{a m b}{ }^{4}\right)}+\Delta \alpha_{s, n-g}\left(T_{s}\right) \frac{T_{a m b}{ }^{4}}{\left({T_{s}}^{4}-T_{a m b}{ }^{4}\right)}
$$

where $A_{s}$ is the area of each sample surface, and $\sigma$ is the Stefan-Boltzmann constant. The second term on the right-hand side appears due to possible non-gray spectral optical properties of a surface. Here $\Delta \alpha_{s, n-g}\left(T_{s}\right)=\varepsilon_{s}\left(T_{s}\right)-\alpha_{s, T_{a m b}}\left(T_{s}\right)$ is the difference between the total hemispherical absorptance, $\alpha_{s, T_{a m b}}\left(T_{s}\right)$, of a sample at $\mathrm{T}_{\mathrm{s}}$ for the irradiation from the blackbody surrounding at $\mathrm{T}_{\mathrm{amb}}$ and the total hemispherical emittance, $\varepsilon_{s}\left(T_{s}\right)$, of the sample at $\mathrm{T}_{\mathrm{s}}$. For the proposed method the non-gray surface term is neglected as it is typically done for calorimetric techniques to simplify the analysis. In fact, it is not possible to accurately calculate $\Delta \alpha_{\mathrm{s}, \mathrm{n}-\mathrm{g}}$ without performing high temperature radiometric emission measurements to obtain the spectral hemispherical emittance or without a method that can directly measure the total hemispherical absorptance of a sample at elevated temperature for the incident wavelength spectrum of a blackbody near room temperature. However, neglecting the non-gray term is a reasonable assumption for surfaces which can typically be approximated as gray surfaces, e.g. metals, especially at high temperatures. For wavelength selective solar absorbers on the other hand a significant error can be introduced as has been shown theoretically for ideal spectrally selective surfaces [31]. Thus, in this work an estimate of this error is added to the error bars of the measurement results as will be discussed in section 3.1. 


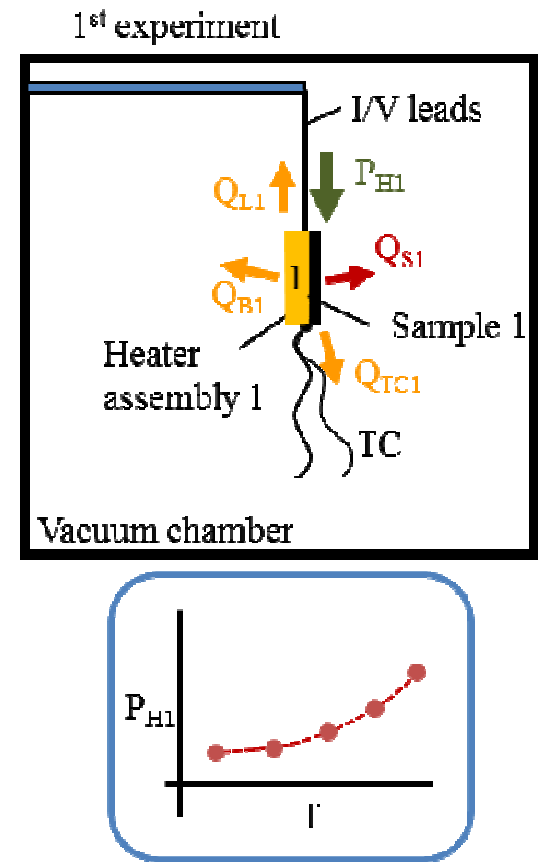

$3^{\text {rd }}$ experiment (calibration)
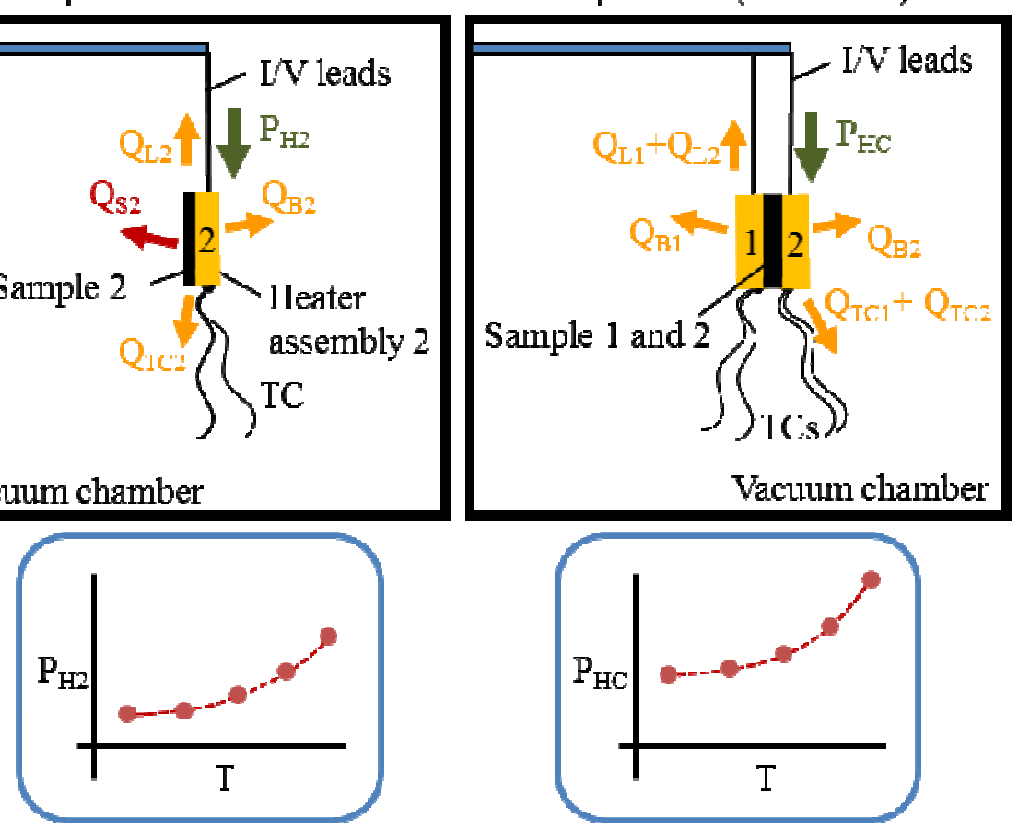

Fig. 1: Methodology of the proposed steady-state calorimetric emission measurement with calibration step. The method consists of 3 consecutive experiments using two identical heater assemblies 1 and 2 and two identical samples. The sample temperatures are measured with thermocouples (TCs). In the $1^{\text {st }}$ and $2^{\text {nd }}$ experiment one sample-heater assembly is suspended in a large stainless steel vacuum chamber which acts as a blackbody surrounding at constant temperature. The sample is heated to several set temperatures by controlling the electrical heater power input $\mathrm{P}_{\mathrm{H}}$ such that it balances the radiation heat loss from the sample, $\mathrm{Q}_{\mathrm{S}}$, and the parasitic heat loss including the radiation from the back side and the edges, $\mathrm{Q}_{\mathrm{B}}$, as well as conduction losses, $\mathrm{Q}_{\mathrm{L}}$, through $\mathrm{I} / \mathrm{V}$ leads and $\mathrm{Q}_{\mathrm{TC}}$, through thermocouple wires. The heater input power is recorded for several sample set temperatures, $\mathrm{T}$, after the sample-heater assembly reaches a steady state. The purpose of the $3^{\text {rd }}$ experiment is to calibrate for all parasitic heat losses. The two samples are sandwiched between the two heater assemblies to only eliminate the radiation from their surfaces, $\mathrm{Q}_{\mathrm{S} 1}$ and $\mathrm{Q}_{\mathrm{S} 2}$. The electrical heater power input, $\mathrm{P}_{\mathrm{HC}}$, is recorded at the same steady-state sample set temperatures. The difference between the collective heater power input of the first two experiments and the heater power input in the $3^{\text {rd }}$ experiment corresponds to the radiation heat loss from the sample surfaces which can be related to the total hemispherical emittance.

Even though the discussed method calibrates for the parasitic heat losses, the sample-heater assemblies are designed and fabricated such that the parasitic heat losses are minimized as much as possible to maximize the sample-to-parasitic heat loss ratio (Fig. 2) and minimize error. This becomes especially important for sample surfaces with low emittance. For the heater assembly a flat rectangular copper enclosure is machined ( $53 \mathrm{~mm} \times 31.5 \mathrm{~mm} \times 3 \mathrm{~mm}$ ) to fit a thin rectangular ceramic platinum heater $(48 \mathrm{~mm} \times 28 \mathrm{~mm} \times 2 \mathrm{~mm}, \sim 400 \Omega$ electrical resistance at $295 \mathrm{~K}$ ) to ensure sample temperature uniformity (Fig. 2A). A $125 \mu \mathrm{m} \mathrm{K}$-type thermocouple with special limits of error (SLE temperature uncertainty is the larger of $\pm 1.1^{\circ} \mathrm{C} / \pm 0.004 \cdot \mathrm{T}_{\text {reading }}\left({ }^{\circ} \mathrm{C}\right.$ )) is threaded through a two-hole ceramic insulating tube and embedded in a $15 \mathrm{~mm}$ long slot milled into the copper enclosure to ensure minimal heat flux through the thermocouple bead for accurate temperature measurements. For excellent thermal contact between the ceramic heater and the copper enclosure a thin film of liquid metal $\left(\mathrm{Ga}_{75.5} \mathrm{In}_{24.5}\right)$ is applied as the thermal 

good and stable thermal contact the ceramic heater is pressed against the copper enclosure by means of a copper lid which is bolted down with six bolts (Fig. 2C). Additionally, the liquid metal reacts with the ceramic heater surface and the copper enclosure at elevated temperatures and forms a solid thermally-conductive bonding layer. (An attempt was also made to bond the ceramic heater to the copper enclosure using a braze metal. However, the large stresses due to the thermal expansion mismatch between the ceramic and the copper broke the heater.) The importance of good and stable thermal contacts for the experiments is discussed in section 2.3. After a sample (in Fig. 2D it is a mechanically polished stainless steel sample) is attached to the heater assembly, it is suspended in the vacuum chamber (brushed stainless steel, $\sim 61 \mathrm{~cm}$ cube, $\sim 1.9 \mathrm{~cm}$ wall thickness) with two $250 \mu \mathrm{m}$ tantalum wires. The electrical heater power is supplied through $125 \mu \mathrm{m}$ copper wires and the temperature is measured with the embedded K-type thermocouple (Fig. 2D). The total wire heat losses were estimated to be below $10 \%$ of the total parasitic heat losses for the sample-heater assembly. The electrical resistance of the current carrying copper wires is less than $0.5 \%$ of the resistance of the ceramic heater. Thus, the change in Joule heating in the current carrying copper wires due to the difference in the supplied currents between the first two experiments and the calibration experiment is negligibly small and does not affect the power measurement. The samples are large enough to completely cover one side of the heater assemblies and have a thickness of $\sim 1 \mathrm{~mm}$ leading to an overall sample-heater assembly thickness of $\sim 4.5 \mathrm{~mm}$. The samples are attached to the heater assemblies with liquid metal $\left(\mathrm{Ga}_{75.5} \operatorname{In}_{24.5}\right)$ as the adhesion and TIM layer. Before performing the experiments an annealing step at elevated temperature $\left(\sim 1 \mathrm{hr}\right.$ at $\left.\sim 500^{\circ} \mathrm{C}\right)$ is required which allows the liquid metal to react with the surfaces of the heater assembly (electroplated with nickel) and the metal substrate of the sample to form a solid bond. The sample surface is shielded during that process to prevent the deposition of evaporated material. Besides good mechanical strength, the solid interface reaction layer provides excellent thermal contact, making an additional sample temperature measurement redundant as will be shown in section 3.3. Consequently, the thermocouples embedded in the heater assemblies are used to measure the sample temperatures. For the heat loss calibration measurement ( $3{ }^{\text {rd }}$ experiment) the sample-heater assemblies are attached to each other on the sample surface with liquid metal and annealed (Fig. 2E). It is important that the sample surfaces are of the same size, are flat and are accurately aligned with each other to completely eliminate the sample surface radiation. Also, the optical properties of all other surfaces must not be affected (e.g. by spillage of liquid metal on the side walls of the heater assembly) during this process to ensure unaltered parasitic heat losses. This is confirmed by a heat loss measurement before and after the annealing process, which showed a change in the required power input of less than $0.5 \%$. For the advantage of being able to reuse the heater assemblies the solid liquid metal bonding layers turn out to be weak enough for the samples to be removed after the experiments without damaging the heater assemblies. 

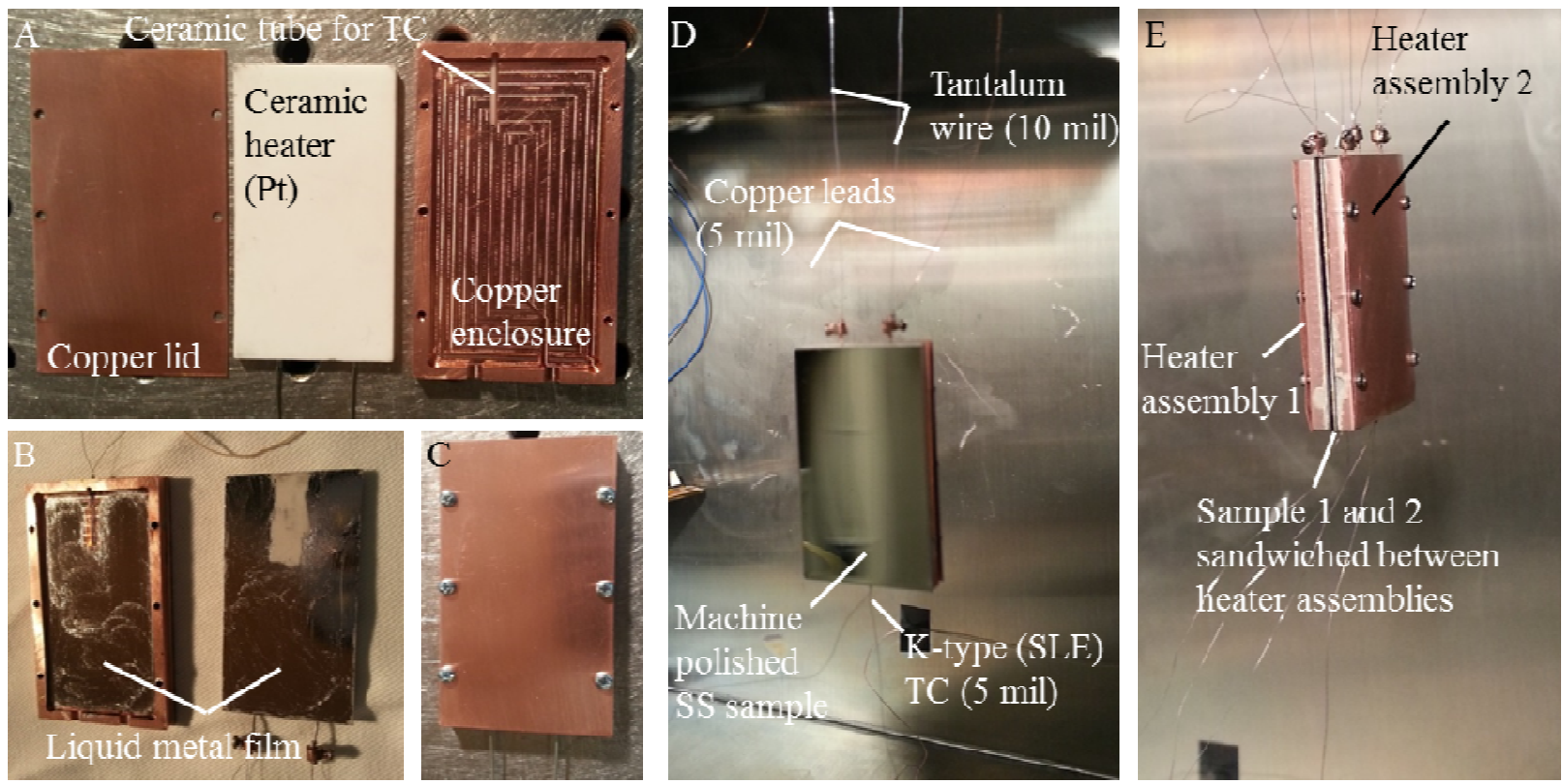

Fig. 2: Experimental setup. (A) A pocket is milled into a copper sheet to enclose a high temperature thin rectangular ceramic platinum heater with a copper lid. A slot is milled into the copper enclosure to embed a thermocouple (TC) with an insulating ceramic tube. (B) Liquid metal $\left(\mathrm{Ga}_{75.5} \mathrm{In}_{24.5}\right)$ films cover the ceramic heater and the inside of the copper enclosure to ensure excellent thermal contact. (C) The ceramic heater is pressed against the copper enclosure with the copper lid for stable thermal contact. (D) A machine-polished stainless steel (SS) sample is attached to the heater assembly with liquid metal. The sample temperature is measured with the $125 \mu \mathrm{m}$ K-type TC (SLE) embedded in the heater assembly. The assembly is suspended with two $254 \mu \mathrm{m}$ tantalum wires and the electrical heater current is supplied via two $125 \mu \mathrm{m}$ copper leads. (E) Setup configuration of calibration measurement. Samples are sandwiched between the heater assemblies to eliminate the radiation from their surfaces. Liquid metal is used to attach the two sample surfaces to each other.

In order to provide the electrical power to the heater with high accuracy the electrical heater current is supplied with precision power supplies by Keithley with $\mu$ A resolution (model 2425) and the voltage is measured with a precision digital multimeter (DMM) by Keithley with $\mathrm{nV}$ resolution (model 2010 with scanner card). The same DMM is used to perform all temperature measurements with high accuracy. The cold junctions of the thermocouples are thermally grounded to a vacuum chamber wall and its temperature is measured with a resistance temperature detector (RTD) which was calibrated with a thermistor with an accuracy of $\pm 0.2^{\circ} \mathrm{C}$. Thus, the measured temperature is used as the cold junction compensation as well as the surrounding temperature, $T_{a m b}$, during the experiments. The experiments are controlled with LabVIEW and the electrical heater power input, sample temperature, and surrounding temperature is recorded when the sample-heater assembly reaches thermodynamic equilibrium with the surrounding at each sample set temperature from 100 to $500{ }^{\circ} \mathrm{C}$ in $100^{\circ} \mathrm{C}$ increments. The sample-heater assembly temperatures are controlled to below $0.05 \%$ discrepancy from the set temperature in all three experiments to ensure unchanged parasitic heat losses. 


\subsection{Solar absorptance measurement technique}

Besides the total hemispherical emittance, the solar absorptance is the other important optical property necessary to characterize a solar absorber. Thus, we introduce a simple technique to measure the solar absorptance of a surface at elevated temperature using the same heater assembly described in section 2.1 (Fig. 3). Similar to the emittance measurement method the sample-heater assembly is suspended in a vacuum chamber with the sample surface facing a fused silica viewport (Fig. 3A-2) through which the light beam from a solar simulator (class AAA) can enter the chamber and irradiate the sample surface (Fig. 3A). The sample is illuminated with various incident radiation powers, $Q_{\text {sol }}$, and maintained at a constant elevated steady-state sample set temperature, $\mathrm{T}_{\mathrm{s}}$, by varying the electrical power, $\mathrm{P}_{\mathrm{H}}$, to the heater assembly accordingly. The temperature is measured with the K-type thermocouple embedded in the heater assembly and the same instruments are used to provide and measure the electrical heater power input as describe in section 2.1. LabVIEW is used to control the experiments. The incident solar radiation powers are measured with a thermopile detector (Model: 818P-040-55) and power meter (Model: 1918-R) from Newport inside the vacuum chamber close to the location of the sample before evacuation. Despite the use of an accurate solar simulator the broad wavelength spectrum of the output beam and the spectral response of the thermopile detector must be known to minimize the error from these measurements. The recorded electrical heater power should show a linear dependence on the incident solar radiation power and the slope of the linear fit yields the solar absorptance (Fig. 3B):

$$
\alpha_{\text {sol }}=\left|\frac{d P_{H}}{d Q_{s o l}}\right|
$$

Significant thermal resistances within the sample-heater assembly cause changing surface temperatures upon varying incident solar radiation power as will be discussed in section 2.3. This can introduce a non-linearity in the electrical heater power versus incident solar radiation power measurements due to the $\mathrm{T}^{4}$ - dependence of the changing radiation heat losses. Therefore, low thermal resistances within the sample-heater assembly are essential for the accuracy of not only the emittance but also for the solar absorptance measurement as will be discussed in section 2.3 and 3.3. A $75 \mathrm{~mm}$ diameter N-BK7 lens (Fig. 3A-1) is used to focus the light beam to increase the solar radiation power input for a reasonable signal-to-noise ratio and to prevent spillage of light that could introduce a significant error in the measured incident solar radiation power. For the purpose of a more uniform sample illumination to minimize temperature gradients the sample is not placed at the focal point of the lens and a rectangular aperture (1) is used to give the light beam a rectangular shape (Fig. 3A-3). The divergence half-angle of the solar simulator light incident on the sample is approximately $15^{\circ}$. The chamber walls are covered with a diffuse black tape and the viewport is shielded with a graphite coated copper plate which is thermally grounded to the chamber walls to minimize back reflection of light (Fig. 3A-4). A rectangular aperture (2) in the coated copper plate allows the solar radiation to pass through to the sample. The fused silica viewport and the N-BK7 lens are chosen for their flat spectral transmittance in 
the solar wavelength range in order for them not to significantly affect the radiation spectrum of the solar simulator light beam (Fig. 3C).
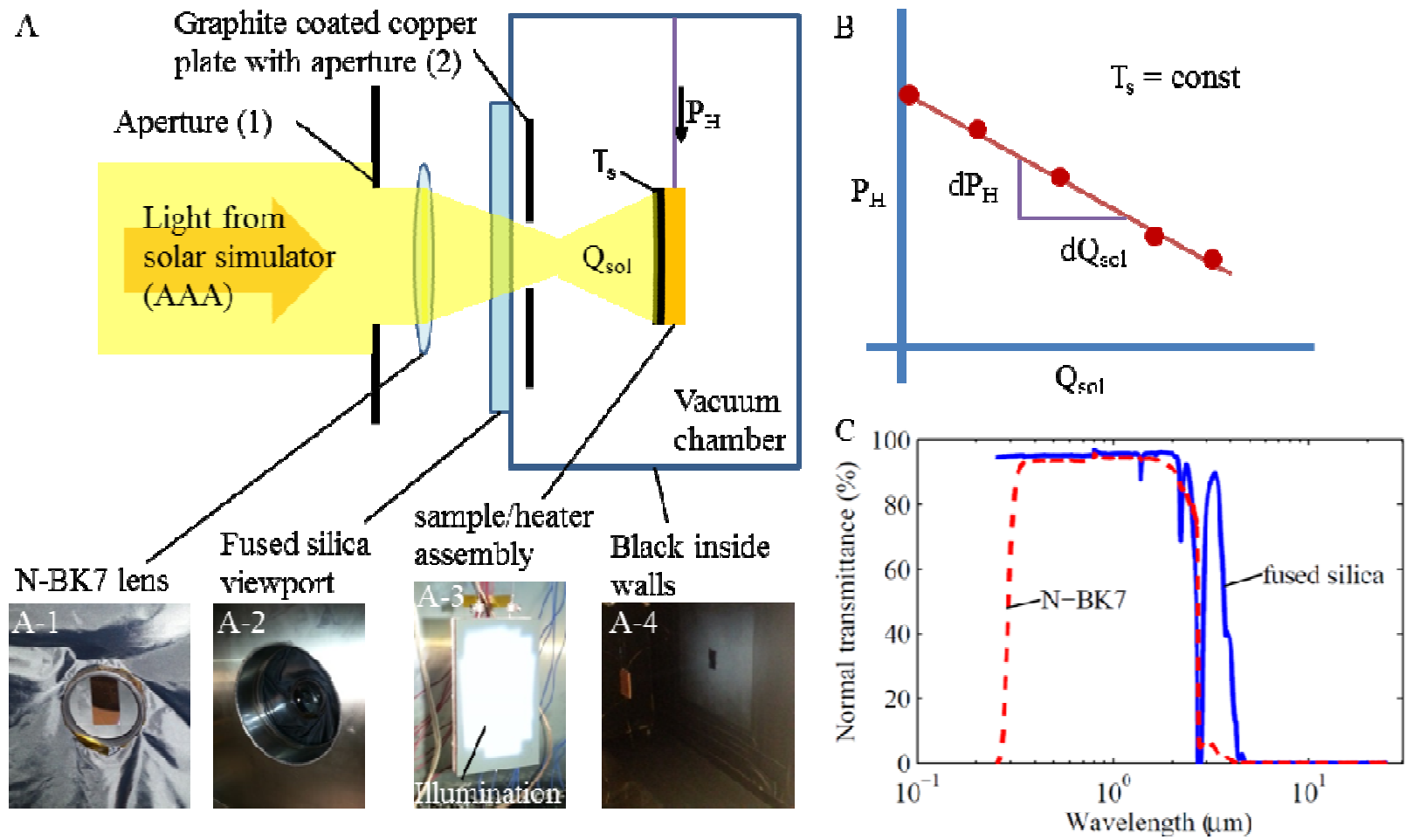

Fig. 3: Solar absorptance measurement technique. (A) Experimental setup: sample-heater assembly is suspended in a vacuum chamber with diffuse black walls with the sample facing a fused silica viewport (A-2). Its temperature, $T_{s}$, is controlled with the electrical heater power input, $\mathrm{P}_{\mathrm{H}}$. The light from the solar simulator incident on the sample surface, $Q_{\text {sol }}$, is focused through an N-BK7 lens (A-1). The primary aperture (1) shapes the light beam to match the rectangle sample surface to avoid light spillage and to ensure uniform sample illumination (A-3). A graphite coated copper plate with a second aperture (2) minimizes back reflection of light (A-4). The incident radiation power inputs are measured with a thermopile and power meter inside the vacuum chamber before evacuation. (B) The electrical heater power input, $\mathrm{P}_{\mathrm{H}}$, is controlled to maintain a constant sample temperature, $\mathrm{T}_{\mathrm{s}}$ for various incident solar radiation power inputs, $\mathrm{Q}_{\text {sol }}$, and thus $\mathrm{P}_{\mathrm{H}}$ should show a linear dependence on $\mathrm{Q}_{\text {sol. }}$. The slope $\left|\mathrm{dP}_{\mathrm{H}} / \mathrm{dQ}_{\mathrm{sol}}\right|$ of the linear fit equals the solar absorptance. (C) Measured spectral transmittance data of N-BK7 lens and fused silica viewport. The flat spectral transmittance in the solar wavelength range minimizes the effect on the output radiation spectrum of the solar simulator.

\subsection{Method to probe thermal contacts to validate accurate measurements}

As described in section 2.1, the ceramic heater is surrounded by a copper enclosure and the sample substrates are metals with a high enough thermal conductances $G=\frac{\text { thermal conductivity }}{\text { substrate thickness }}$ to minimize temperature gradients within the sample-heater assembly (Fig. 4A). Even for a relatively low thermally-conductive metal substrate such as stainless steel with thickness of $0.8 \mathrm{~mm}$ at $500{ }^{\circ} \mathrm{C}$ with a black coating $(\varepsilon=1)$, the temperature drop and error in emittance does not exceed $0.6^{\circ} \mathrm{C}$ and $0.3 \%$, respectively. For typical solar absorbers with emittance values of below 0.25 the error in emittance will not exceed $0.1 \%$. The thermal resistances of the 

nanometers are negligible. However, there are two crucial interfaces with unknown thermal resistances that could create temperature gradients and affect the experiments (Fig. 4B): (1) the interface between the ceramic platinum heater and the copper enclosure (I1) with thermal resistance $\mathrm{R}_{\mathrm{I} 1}$ and (2) the interface between the copper enclosure and the sample (I2) with thermal resistance $\mathrm{R}_{\mathrm{I} 2}$ (Fig. 4C). A good and stable thermal contact at those interfaces is a strict requirement to prevent a change in parasitic heater losses during the total hemispherical emittance and solar absorptance experiments. Additionally, if $\mathrm{R}_{\mathrm{I} 2}$ is negligibly small the sample temperature can conveniently be measured with the thermocouple embedded in the copper enclosure of the heater assembly $\left(\mathrm{T}_{\mathrm{E}} \approx \mathrm{T}_{\mathrm{S}}\right)$ without losing measurement accuracy.

The following experimental method enables the probing of those interface resistances (Fig. 4). It is based on the same experimental setup developed for the solar absorptance measurement (Fig. $3 \mathrm{~A})$. However, the sample-heater assembly is slightly modified by attaching thermocouples to the copper lid and the sample surface (Fig. 4B and D). The sample-heater assembly is then suspended in the vacuum chamber as described in sections 2.1 and 2.2. The temperature of the copper enclosure is raised to several steady-state set temperatures with and without solar radiation power, $\mathrm{Q}_{\text {sol }}$, incident on the sample surface. When the system reaches a steady state the heater power input, heater resistance, the temperatures of the copper enclosure, $\mathrm{T}_{\mathrm{E}}$, the sample surface, $T_{s}$, and the copper lid, $T_{L}$, are recorded. By varying the incident solar radiation power $\left(\mathrm{Q}_{\text {sol }}\right.$ on/off) and maintaining the sample-heater assembly at the same temperature the net heat flow from the sample surface changes. This inevitably leads to a change in heat flow through the interfaces I1 and I2 (Fig. 4B and C). Additionally, if the thermal interface resistance, $\mathrm{R}_{\mathrm{Il}}$ is not negligible the ceramic heater temperature, $\mathrm{T}_{\mathrm{H}}$, changes upon a changing power input which causes $\mathrm{T}_{\mathrm{L}}$ and the heat flow $\mathrm{Q}_{\mathrm{L}}$ through the interface $\mathrm{I} 3$ (with thermal resistance $\mathrm{R}_{\mathrm{I}}$ ) to change as well. A varying ceramic heater temperature can be detected with a corresponding change in electrical heater resistance $R_{H}\left(T_{H}\right)$. Thus, while $T_{E}$ is maintained constant, seeing a change in $T_{s}$, $T_{L}$, and $R_{H}\left(T_{H}\right)$ with changing net heat flow $\left(Q_{s}-\alpha_{s, s o l} Q_{s o l}\right)$ from the sample surface is an indication for significant thermal interface resistances which would cause changing parasitic heat losses and introduce errors in the emittance and solar absorptance experiments. The experiment to probe the thermal resistances is performed with a reference black paint (HE6 from Rolls Royce, $\alpha=\varepsilon \approx 0.95$ ) to maximize the change in heat flow through the interfaces with varying $\mathrm{Q}_{\text {sol. }}$. 

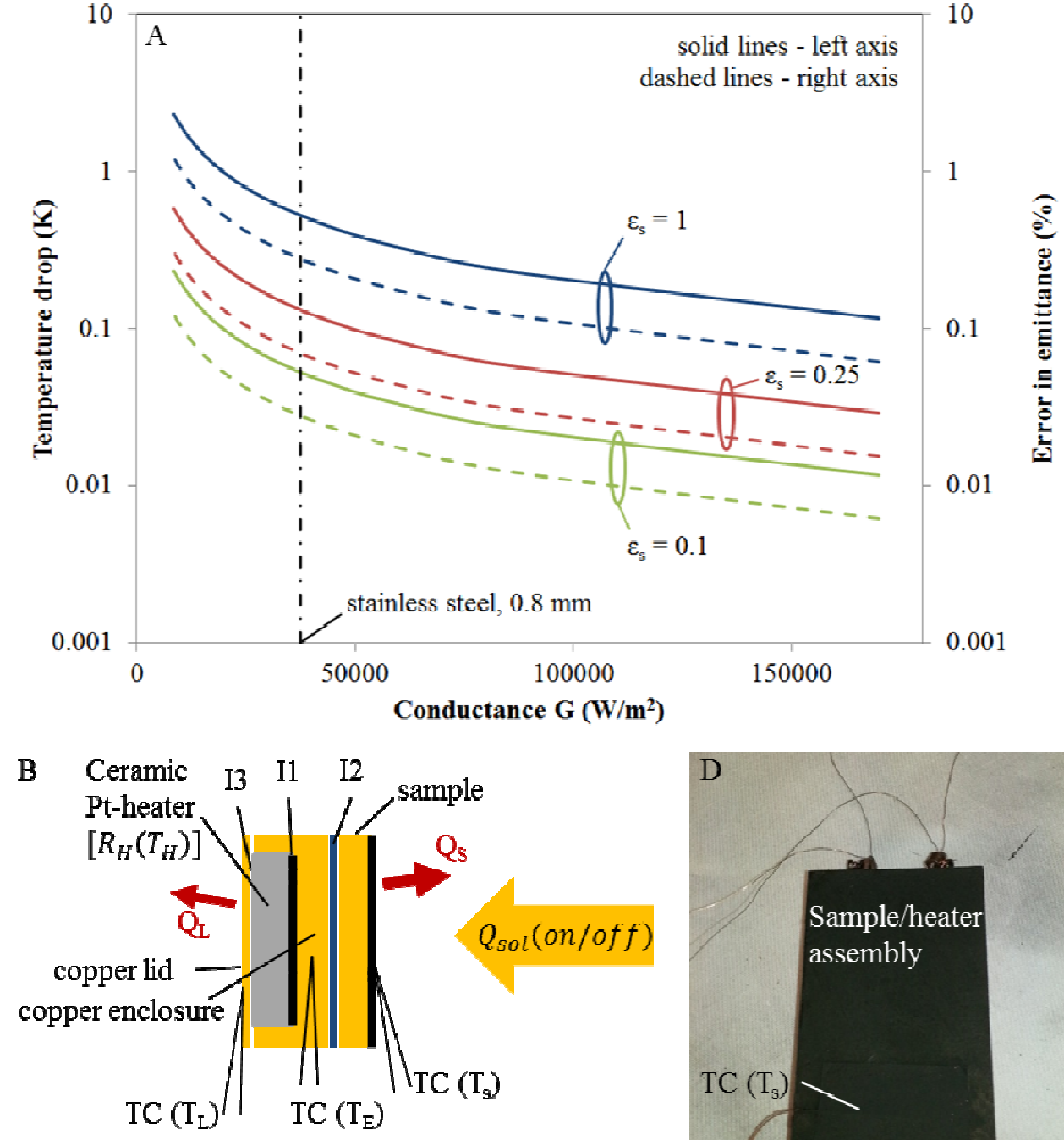

C
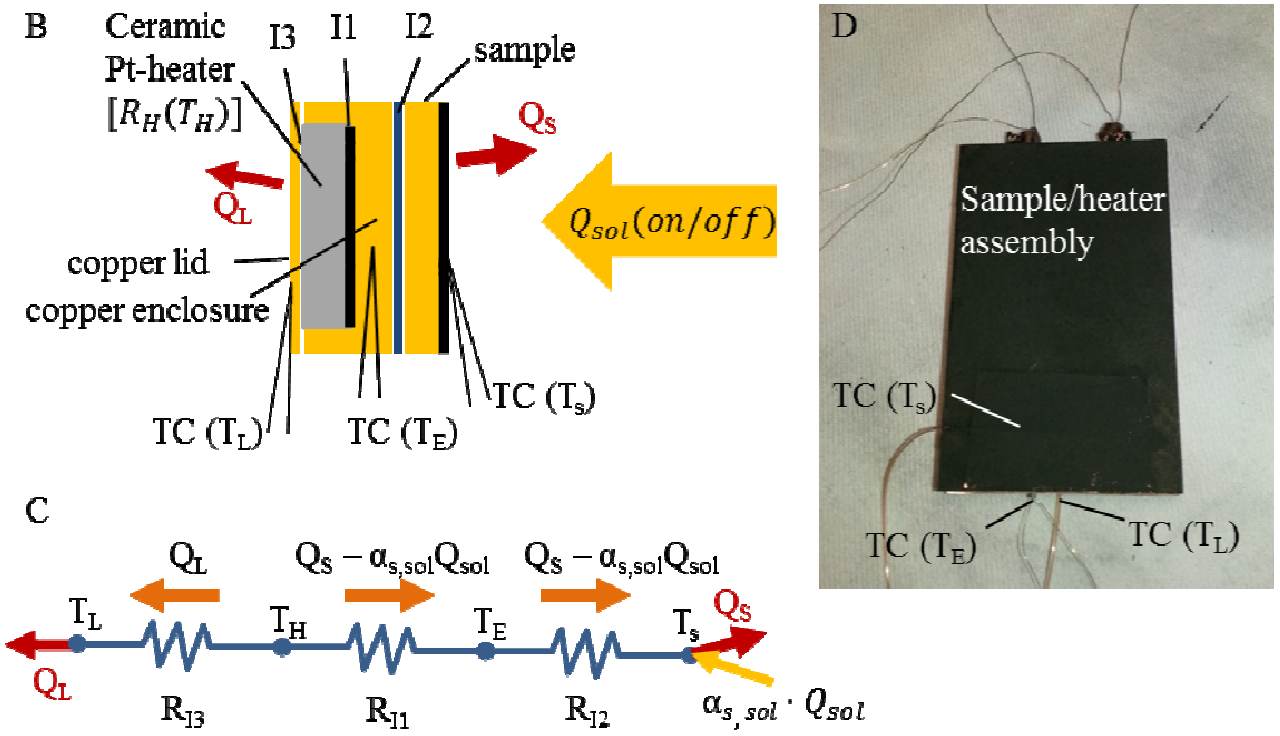

Fig. 4: Methodology to probe the effect of thermal interface resistances and to validate accurate temperature measurement. (A) Temperature drop across the sample substrate and resulting error in emittance at $500{ }^{\circ} \mathrm{C}$ as a function of the thermal conductance of the sample substrate for various sample surface emittances. (B) Basic experimental concept: in addition to the thermocouple (TC) embedded in the heater assembly $\left(T_{E}\right)$ which is used for the actual emittance/absorptance experiments, a thermocouple is directly attached to the sample surface and the back side copper lid to measure their temperatures $\mathrm{T}_{\mathrm{S}}$ and $\mathrm{T}_{\mathrm{L}}$. The sample-heater assembly is suspended in a vacuum chamber and raised to elevated temperature with and without illumination, $\mathrm{Q}_{\text {sol }}$, from the solar simulator. The heat flows through the interfaces I1 and I2 are varied by changing the net heat flow which is determined by the emitted sample radiation, $\mathrm{Q}_{\mathrm{s}}$, and $\alpha_{\mathrm{s}, \mathrm{sol}} \cdot \mathrm{Q}_{\mathrm{sol}}$ with $\alpha_{\mathrm{s}, \mathrm{sol}}$ being the solar absorptance of the surface. The heat flow, $\mathrm{Q}_{\mathrm{L}}$, from the copper lid and through interface $\mathrm{I} 3$ changes when the ceramic heater temperature, $\mathrm{T}_{\mathrm{H}}$, varies upon changing $\mathrm{Q}_{\text {sol }}$. (C) Thermal resistance network of the experimental setup. (D) Sample-heater assembly with reference black paint (HE6 from Rolls Royce, $\alpha=\varepsilon \approx 0.95$ ) coated on copper substrate ( $0.8 \mathrm{~mm}$ thick) as the sample surface. 


\section{Results and discussion}

\subsection{Total hemispherical emittance}

Several samples are measured with the introduced total hemispherical emittance measurement method (Fig. 5). The error bars include the errors from the temperature measurements, electrical heater power measurements, sample surface area measurements, and in the case of the spectrally selective solar absorber sample measurements the error from the gray body assumption. The uncertainty in the temperature measurement is composed of the statistical measurement error of the recorded sample and wall temperatures and the systematic errors from the two thermocouples embedded in the heater assemblies and the RTD to measure the vacuum chamber wall temperature. The statistical temperature measurement error is determined by adding the standard deviation of each temperature measurement. As described in section 2.1, K-type thermocouples with special limits of error are embedded in the copper heater enclosure to minimize the systematic error of each thermocouple to the larger of $\pm 1.1{ }^{\circ} \mathrm{C}$ or $\pm 0.004 \cdot \mathrm{T}_{\text {reading }}\left({ }^{\circ} \mathrm{C}\right)$. The wall temperature which is also the cold junction compensation temperature is measured with a calibrated RTD with an uncertainty of $\pm 0.2{ }^{\circ} \mathrm{C}$. The change in emittance of a surface as a function of temperature can be attributed to two main effects: (1) The temperature dependence of the optical constants resulting in a change in the spectral emittance with varying temperature; (2) The non-gray spectral optical properties of a surface which cause a change in total emittance due to the shift of the blackbody spectrum with changing temperature. Metals can typically be approximated as gray bodies and thus the changing emittance is mostly attributed to the temperature dependence of the optical constants. However, for other surfaces, in particular for spectrally selective solar absorbers, the second effect will also contribute to the temperature dependence of the emittance. These two effects are seen in the measurements shown in Fig. 5. For example, from 100 to $500{ }^{\circ} \mathrm{C}$ the emittance of the (approximately gray) copper substrate changes by about 0.012 , whereas the emittances of the (non-gray) solar absorbers with copper substrates change by approximately 0.08 . The difference between these two changes in emittance can be attributed to the non-gray spectral properties of the surface, and is called the non-gray contribution. It is this non-gray contribution with respect to ambient temperature which appears in the second term on the right-hand side of equation (2). For the selective surfaces measured in this study, the error from ignoring this term significantly contributes to the calculated total relative error of $1-5 \%$ for the measured surfaces at temperatures from $100-$ $500{ }^{\circ} \mathrm{C}$.

The emittance of the mechanically polished copper and stainless steel sample shows a linear temperature dependence as it is expected for metals from theory [50]. Our experimental copper data are in good agreement with data reported in literature such as the data measured by Smalley [36] who used a transient calorimetric method on a flat mechanically polished copper sheet and found good agreement with established theory. Three spectrally-selective solar absorbers on two different substrates are measured including one commercial solar absorber on a copper substrate. The fabricated solar absorber samples are based on double layer cermet structures with two 

steel (UH 2) samples. The emittances of the commercial and fabricated solar absorbers on copper show similar values starting with approximately 0.07 at $100{ }^{\circ} \mathrm{C}$ and peaking with about 0.15 at $500{ }^{\circ} \mathrm{C}$. The solar absorber on stainless steel shows higher emittance values due to the significantly higher emittance and steeper temperature dependence of the stainless steel substrate. For this solar absorber we can conclude that the emittance is mostly determined by the stainless steel substrate, whereas for the solar absorbers on copper the cermet double layers make a relatively large contribution to the emittance. Thus, the typical deviation from the linear temperature dependence of the emittance due to the cermet double layer induced spectral selectivity is less pronounced for the solar absorber with a stainless steel substrate compared to that with a copper substrate.

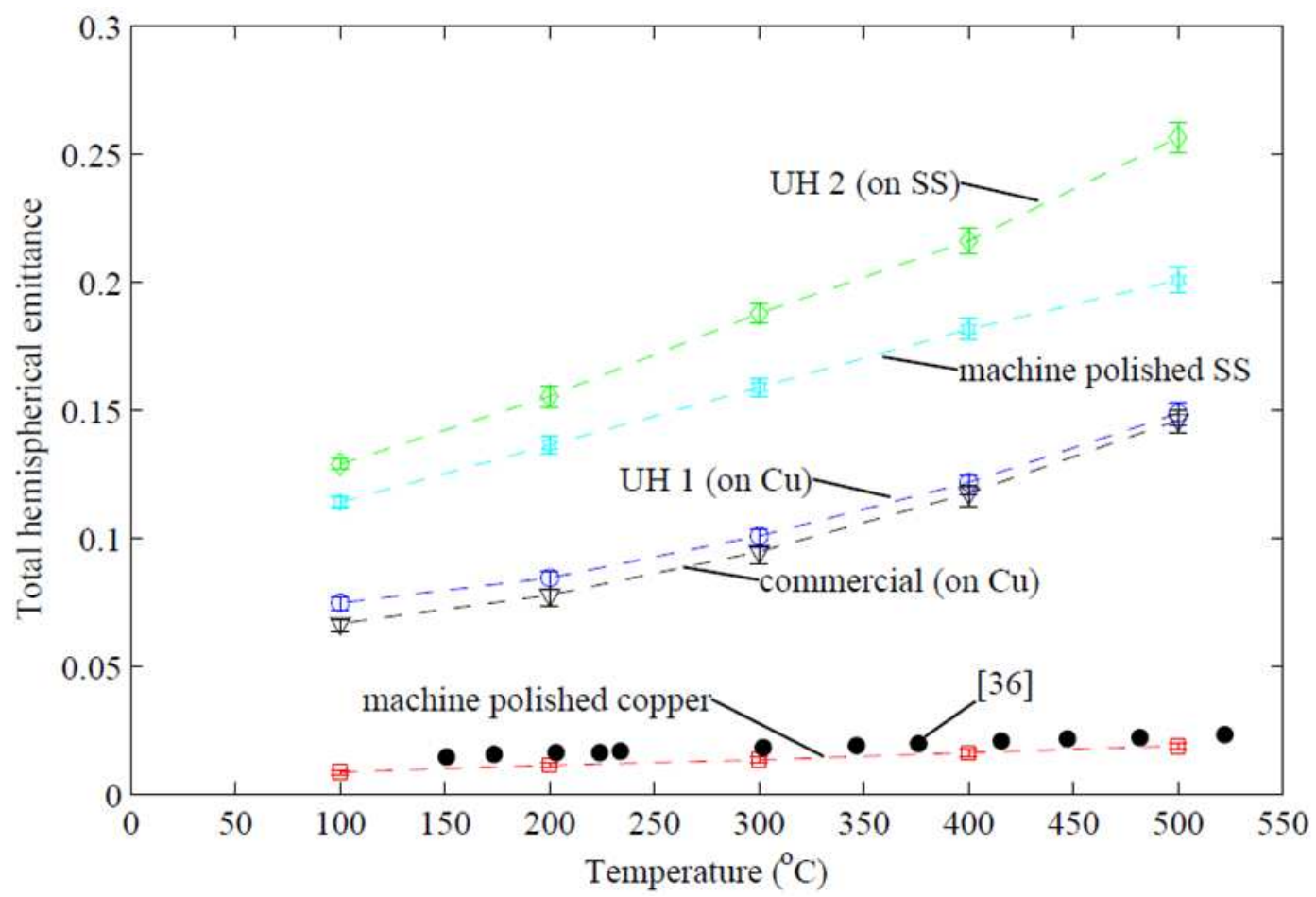

Fig. 5: Total hemispherical emittance results for machine polished copper (red squares), machine polished stainless steel (cyan hexagons), commercial spectrally selective solar absorber on copper substrate (black triangles), fabricated cermet-based wavelength selective solar absorbers on a copper substrate (blue circles) and on a stainless steel substrate (green diamonds).

\subsection{Solar absorptance}

In order to demonstrate the solar absorptance measurement method, a reference black paint by Rolls Royce (HE6) is measured at $100{ }^{\circ} \mathrm{C}, 200{ }^{\circ} \mathrm{C}$, and $300{ }^{\circ} \mathrm{C}$ (Fig. 6). Three coatings of the black paint are applied onto a mechanically polished copper substrate which was cleaned with isopropanol and distilled water prior the application of the paint. The experimental results are limited to a maximum temperature of $300^{\circ} \mathrm{C}$ due to the stability of the paint. Increasing the temperature to $400{ }^{\circ} \mathrm{C}$ leads to cracking of the paint which we believe is caused by the difference 

recorded electrical heater input power shows the expected linear dependence with the incident solar radiation from the solar simulator (Fig. 6A). The slope of the linear fits (Equ. (3)) yields the expected temperature independent solar absorptance of $~ 0.95$ [49] (Fig. 6).
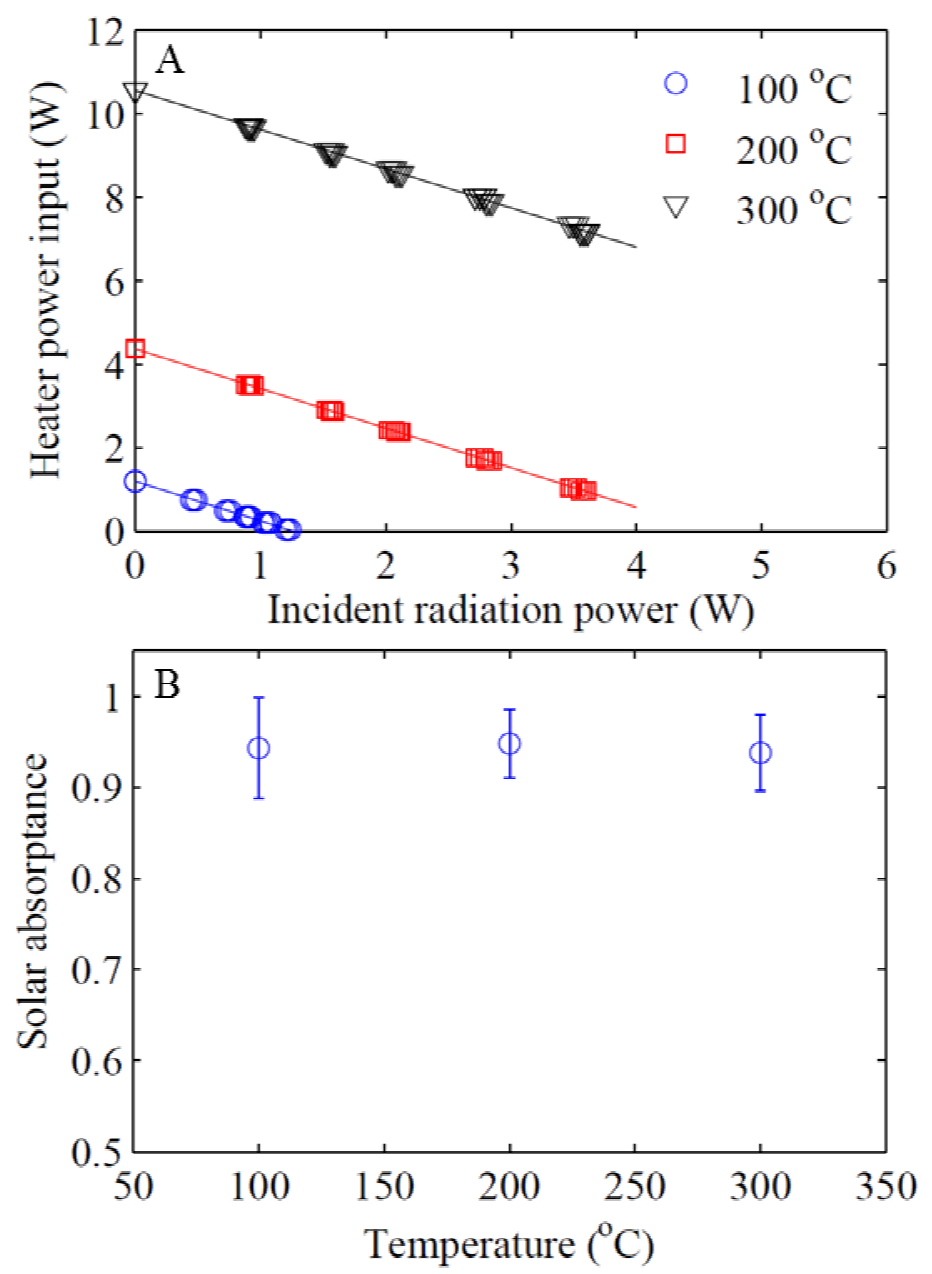

Fig. 6: Solar absorptance results for the reference black paint HE6 by Rolls Royce from $100{ }^{\circ} \mathrm{C}$ to $300^{\circ} \mathrm{C}$. (A) Heater input power shows expected linear dependence on incident radiation power at sample temperatures $100{ }^{\circ} \mathrm{C}$, $200{ }^{\circ} \mathrm{C}$, and $300{ }^{\circ} \mathrm{C}$. (B) Measured solar absorptance agrees with expected temperature independent value of $\sim 0.95[49]$.

The error bars include the error from the incident radiation power measurement and the statistical errors from the temperature and electrical power measurements. The statistical measurement errors are obtained from the upper and lower bounds of the $95 \%$ confidence linear fit results. The largest measurement error of this method, however, stems from the statistical and systematic error of the incident solar radiation power measurement with the thermopile detector $(\sim 2.5 \%)$ and from the temporal stability of the solar simulator $(\sim 2 \%)$. The total maximum relative uncertainty of this method is estimated to be close to $5 \%$. In addition to the reference black paint we use this method to obtain the solar absorptance of a spectrally selective solar absorber sample up to $500{ }^{\circ} \mathrm{C}$ with similar uncertainties as will be discussed in section 3.4. 


\subsection{In situ probing of thermal contacts to validate accurate measurements}

The accuracy of the proposed methods strongly relies on accurate sample temperature measurements and on stable sample-heater assemblies with parasitic heat losses that do not change during the experiments. Negligible thermal interface resistances within the sampleheater assembly are essential to ensure stable parasitic heat losses. In order to probe the thermal contacts and demonstrate their effect two sets of experiments are performed using the described method in section 2.3 (Fig. 7).
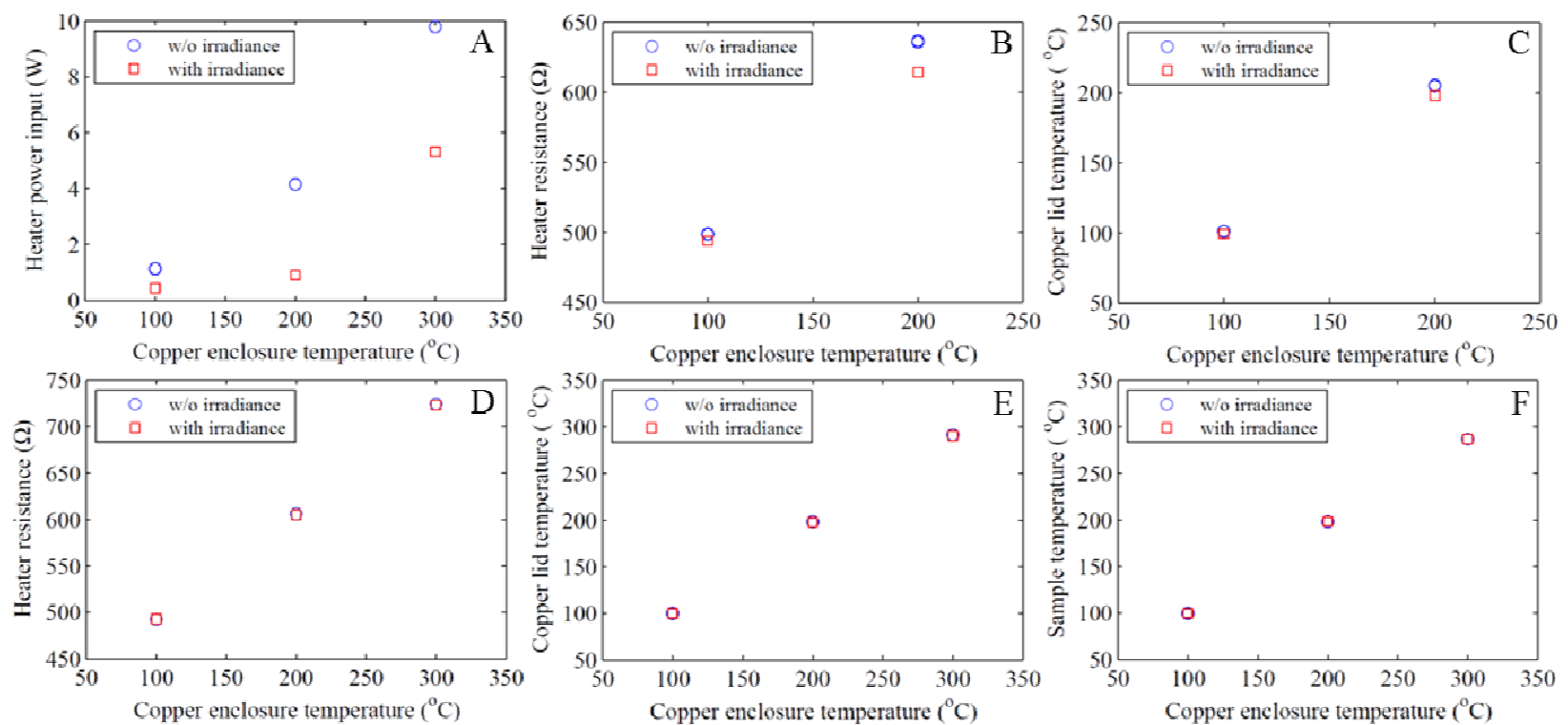

Fig. 7: Experimental results for probing thermal contacts. (A) Heater power input as a function of copper enclosure temperature with and without sample illumination indicating that at least half of the input power can be provided by the solar simulator beam. Thus, the heat flows through the interfaces are significantly altered. (B) A graphite sheet is used as TIM between ceramic heater and copper enclosure. Electrical heater resistance and thus temperature is significantly higher without sample irradiance compared to with illumination illustrating that a graphite sheet introduces a significant thermal interface resistance. As shown in (C), this thermal interface resistance also manifests itself in a larger copper lid temperature when the sample is not illuminated requiring higher heater power input resulting in higher heater temperature. By replacing the graphite sheet with liquid metal as the TIM the ceramic heater resistance and thus its temperature (D) and the copper lid temperature (E) is independent of the incident radiation power suggesting an excellent thermal contact. (F) Sample surface temperature is independent of sample illumination suggesting excellent thermal contact between sample and copper enclosure and validating accurate sample temperature measurement with the thermocouple embedded in the copper enclosure of the heater assembly

For the first set of experiments a graphite sheet $75 \mu \mathrm{m}$ thick is placed in between the ceramic heater and the copper enclosure as the TIM. For the second set of experiments the graphite sheet is replaced with highly thermally-conductive liquid metal as described in section 2.1. The experimental setup is capable of supplying up to $\sim 5.5 \mathrm{~W}$ with the focused light beam from the solar simulator. When the sample is illuminated, more than half of the required input power to maintain the copper enclosure of the heater assembly at the steady-state set temperatures is provided by absorbed radiation (Fig. 7A). This causes a significant change in the net heat flow 
$\left(\mathrm{Q}_{\mathrm{s}}-\alpha_{\mathrm{s}, \mathrm{sol}} \mathrm{Q}_{\mathrm{sol}}\right)$ at the sample surface and with that in the heat flows through the thermal interfaces of the sample-heater assembly. The ceramic heater temperature indicated by the heater resistance and the copper lid temperature are significantly different with and without sample illumination when the graphite sheet is used as the TIM (Fig. 7B and C). Consequently, the thermal interface resistance between the ceramic heater and the copper enclosure is unacceptably large, leading to a significant parasitic heat loss change when the sample surface heat loss is modified. This is not the case when liquid metal is used as the TIM. The electrical heater resistance and with that the heater temperature is independent of sample illumination and so is the copper lid temperature, suggesting excellent thermal contacts (Fig. 7D and E). Additionally, the sample surface temperature is independent of the sample illumination, validating accurate sample temperature measurements with the thermocouple embedded in the copper enclosure of the heater assembly (Fig. 7F). During the actual emittance and solar absorptance experiments the measured electrical heater resistance can conveniently be used as a qualitative indicator for the status of the thermal interface resistances to gain further confidence in the experimental results.

\subsection{Optical characterization of solar absorbers}

Typically solar absorbers are characterized using spectral reflectance measurement methods with the sample at room or slightly elevated temperatures $\left(100^{\circ} \mathrm{C}\right)[9,50]$. The total hemispherical emittance and solar absorptance is then calculated from these data for the actual absorber operation temperature which significantly underestimates the emittance as discussed in section 1. Here, we characterize a wavelength selective solar absorber using our introduced methods to prevent those errors (Fig. 8). The example solar absorber is based on a double-cermet structure consisting of two antireflection coatings, two metal particle filled ceramic host layers with a low and high metal volume fraction (LMVF, HMVF) and an IR reflective layer deposited on a stainless steel substrate (Fig. 8A). The total thickness of the multilayer stack is approximately $420 \mathrm{~nm}$. As a quick screening tool to judge the spectral selectivity of the absorber structure, a single angle spectral bidirectional reflectance measurement is performed at room temperature using a spectrophotometer for the ultraviolet (UV), visible and near infrared wavelength range (Cary500i by Varian, $0.25-1.8 \mu \mathrm{m}, 8^{\circ}$, absolute spectral reflectance accessory) and an FT-IR spectrometer for the mid-infrared (MIR) range (Nicolet 6700 by Thermo Scientific, $1.8-20 \mu \mathrm{m}$, $12^{\circ}$ ) using a gold reference mirror (Fig. 8B). A spectral directional-hemispherical reflectance measurement with the spectrophotometer using an integrating sphere showed negligible diffuse reflection suggesting high sample specularity in the UV to MIR range. The introduced solar absorptance method yields a temperature-independent solar absorptance of $\sim 0.9$ which is close to the calculated value of 0.915 from the spectral reflectance data (Fig. 8C). The total hemispherical emittance measured with our direct and absolute steady-state calorimetric method is significantly higher compared to the calculated emittance using the spectral reflectance data, emphasizing the need to report the total hemispherical emittance data of a solar absorber obtained at operating temperature with a direct method (Fig. 8D). 
A

ARC 1 ARC: 2

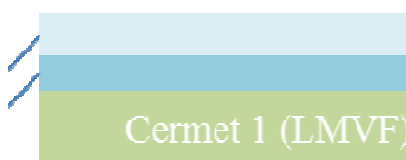

Cermet 2 (HMVF)

$\mathrm{IR}$ reflective layer

Stainless steel substrate

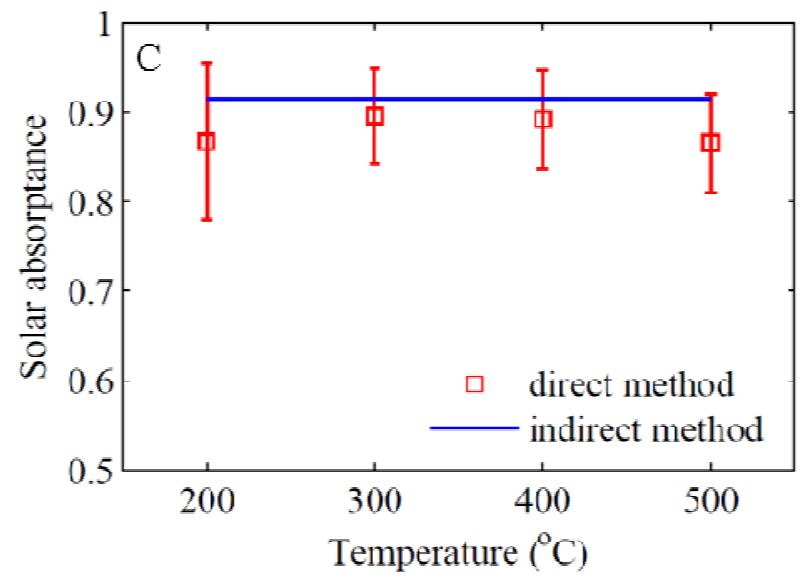

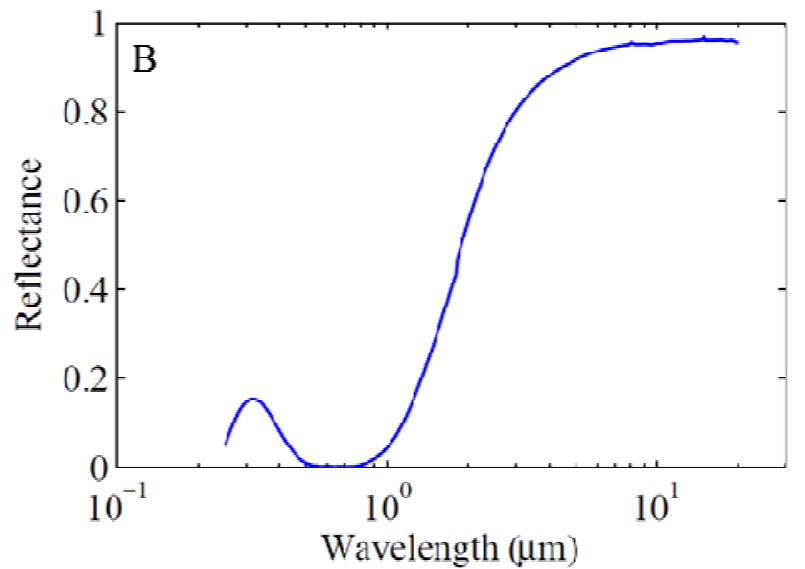

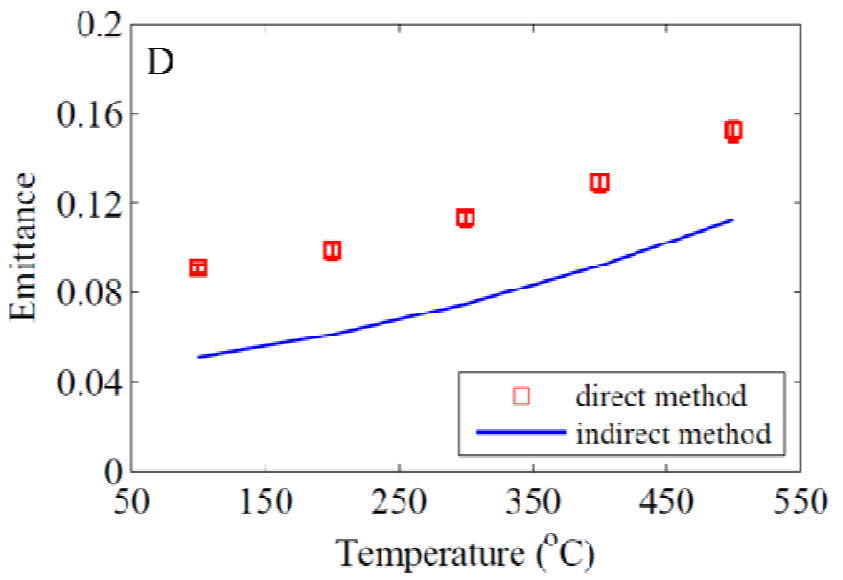

Fig. 8: Characterization of solar absorbers. (A) Example of a double-cermet layer structure on stainless steel substrate with 2 antireflection coatings and IR reflective layer. The thickness of the multilayer stack is $\sim 120 \mathrm{~nm}$ (dielectric multilayers) $+\sim 300 \mathrm{~nm}$ (tungsten IR reflective layer). (B) Spectral near normal bidirectional reflectance using a spectrophotometer $\left(0.25-1.8 \mu \mathrm{m}, 8^{\circ}\right)$ and an FT-IR $\left(1.8-20 \mu \mathrm{m}, 12^{\circ}\right)$. (C) Solar absorptance is temperature independent and agrees with the value calculated from bidirectional spectral reflectance $(0.915 \pm 0.02)$.

(D) Calculated total directional emittance from spectral data and total hemispherical emittance measured with introduced direct steady-state calorimetric method. Calculated total directional emittance significantly underestimates total hemispherical emittance.

\section{Conclusion}

We developed absolute and direct steady-state calorimetric methods to measure the total hemispherical emittance and the solar absorptance of opaque surfaces. We demonstrate the emittance measurement method by measuring several samples including a mechanically polished copper and stainless steel sample and three wavelength-selective solar absorbers from $100{ }^{\circ} \mathrm{C}$ to $500{ }^{\circ} \mathrm{C}$. The measurement results for the mechanically polished copper sample are in good agreement with literature values. The total maximum relative measurement error does not exceed $5 \%$ which mostly stems from the temperature measurement uncertainty and in the case of the solar absorbers from the gray body assumption. The solar absorptance measurement 

$100{ }^{\circ} \mathrm{C}$ to $300{ }^{\circ} \mathrm{C}$. The measurement results agree with the expected temperature independent solar absorptance of $\sim 0.95$. The maximum measurement uncertainty is estimated to be $5 \%$ which is mostly introduced by the incident radiation power measurement and temporal stability of the solar simulator. A spectrally-selective solar absorber based on a double-cermet structure is characterized in terms of its spectral bidirectional reflectance at room temperature using commercial instruments. The calculated solar absorptance of 0.915 is close to the measured temperature-independent solar absorptance using the developed direct method. Comparing the calculated total directional emittance to the measured total hemispherical emittance reveals the expected large discrepancy emphasizing the need to report the total hemispherical emittance data of solar absorbers obtained with a direct calorimetric technique at elevated temperature.

\section{Author contributions}

D. K. developed the method, performed the experiments, analyzed the data and prepared the manuscript. K. M. assisted with method development, troubleshooting of experiments and manuscript preparation. F. C. provided the wavelength selective solar absorber samples. Z.F.R. directed research at UH. G. C. directed research at MIT.

\section{Acknowledgements}

The authors would like to thank Andrej Lenert for discussions on heater assembly development and Dr. Jeffrey Chou and Tim McClure for discussions on spectral reflectance experiments. This work was partially funded by 'Solid State Solar-Thermal Energy Conversion Center ( ${ }^{3}$ TEC)', an Energy Frontier Research Center funded by the US Department of Energy, Office of Science, Office of Basic Energy Sciences under Award Number: DE-SC0001299/DE-FG02-09ER46577 (for method development) and by DOE EERE under Award number: DE-EE0005806 (for solar absorber characterization).

\section{References}

[1] J. Carmody, E. Lee, S. Selkowitz, D. Arasteh, and T. Willmert, Window Systems for High Performance Buildings, 1st ed. New York, NY: W.W. Norton \& Company, Inc., 2004.

[2] S. T. Dunn, J. C. Richmond, and J. F. Parmer, "Survey of Infrared Measurement Techniques and Computational Methods in Radiant Heat Transfer," J. Spacecr. Rockets, vol. 3, no. 7, pp. 961-975, 1966.

[3] J. A. Duffie and W. A. Beckman, Solar engineering of thermal processes, 4th ed. Hoboken, NJ: John Wiley \& Sons, Inc., 2013. 
[4] J. Stefan, "Über die Beziehung zwischen der Wärmestrahlung und der Temperatur," Sitzungsberichte der mathematisch-naturwissenschaftichen Classe der kaiserlichen Akademie der Wissenschaften, vol. 79, no. 2. Wien, pp. 391-428, 1879.

[5] L. Boltzmann, "Ableitung des Stefan'schen Gesetzes, betreffend die Abhängigkeit der Wärmestrahlung von der Temperatur aus der electromagnetischen Lichttheorie," Ann. Phys., vol. 258, no. 6, pp. 291-294, 1884.

[6] M. Planck, "Ueber das Gesetz der Energieverteilung im Normalspectrum," Ann. Phys., vol. 309, no. 3, pp. 553-563, 1901.

[7] M. F. Modest, Radiative Heat Transfer, 2nd ed. San Diego: Academic Press, 2003.

[8] T. S. Touloukian and D. P. Dewitt, Thermophysical Properties of Matter - The TPRC Data Series/Vol 7. Thermal Radiative Properties - Metallic Elements and Alloys, vol. 7. New York: Plenum Pulishing Corp., 1970.

[9] C. E. Kennedy, "Review of Mid- to High- Temperature Solar Selective Absorber Materials," 2002.

[10] J. Strong, Procedures in experimental physics. New York: Prentice Hall, Inc., 1938.

[11] R. C. Birkebak and E. R. G. Eckert, "Effects of Roughness of Metal Surfaces on Angular Distribution of Monochromatic Reflected Radiation," J. Heat Transfer, vol. 87, pp. 85-93, 1965.

[12] K. E. Torrance and E. M. Sparrow, "Off-Specular Peaks in the Directional Distribution of Reflected Thermal Radiation,” J. Heat Transfer, vol. 88, pp. 223-230, 1966.

[13] J. N. Ford, K. Tang, and R. O. Buckius, "Fourier Transform Infrared System Measurement of the Bidirectional Reflectivity of Diffuse and Grooved Surfaces," J. Heat Transfer, vol. 117, pp. 955-962, 1995.

[14] J. R. Zaworski, J. R. Weltyt, and M. K. Drost, "Measurement and use of bi-directional reflectance," J. Heat Mass Transf., vol. 39, no. 6, pp. 1149-1156, 1996.

[15] J. T. Gier, R. V Dunkle, and J. T. Bevans, "Measurement of Absolute Spectral Reflectivity from 1.0 to 15 Microns," J. Opt. Soc. Am., vol. 44, no. 7, pp. 558-561, 1954.

[16] J. E. Janssen and R. H. Torborg, "Measurement of spectral reflectance using an integrating hemisphere," in NASA SP-31 - Measurement of Thermal Properties of Solids, 1963, pp. $169-182$.

[17] R. T. Neher and D. K. Edwards, "Far Infrared Reflectometer for Imperfectly Diffuse Specimens," Appl. Opt., vol. 4, no. 7, pp. 775-780, Jul. 1965. 
[18] D. K. Edwards, J. T. Gier, K. E. Nelson, and R. D. Roddick, "Integrating Sphere for Imperfectly Diffuse Samples," Appl. Opt., vol. 51, no. 11, pp. 1279-1288, 1961.

[19] H. J. McNicholas, “Absolute methods in reflectometry,” Bur. Stand. J. Res., vol. 1, no. 1, pp. 29-73, Jul. 1928.

[20] F. J. J. Clarke and J. A. Larkin, "Measurement of total reflectance, transmittance and emissivity over the thermal IR spectrum," Infrared Phys., vol. 25, no. 1, pp. 359-367, 1985.

[21] G. A. Zerlaut, "An apparatus for the measurement of the total normal emittance of surfaces at satellite temperatures," in NASA SP-31 - Measurement of Thermal Properties of Solids, 1963, pp. 275-285.

[22] S. X. Cheng, S. X. Jing, X. S. Ge, and C. C. Yao, "Method and Apparatus for Determination of the Total Directional Emissivity of Opaque Materials in the Temperature Range 300 to 600 K," Int. J. Thermophys., vol. 15, no. I, pp. 177-187, 1994.

[23] A. V. Dvurechenskii, V. A. Petrov, and V. Y. Reznik, "Measurement of emissivity of partially transparent materials at high temperatures by high-speed spectrometry method," Meas. Tech., vol. 20, no. 10, pp. 1479-1482, 1977.

[24] S. E. Hatch, "Emittance Measurements on Infrared Windows Exhibiting Wavelength Dependent Diffuse Transmittance," Appl. Opt., vol. 1, no. 5, pp. 595-601, 1962.

[25] J. O. Hylton and R. L. Reidf, "System for the Measurement of Spectral Emittance at High Temperature," AIAA J., vol. 14, no. 9, pp. 1303-1310, 1976.

[26] M. A. Postlethwait, K. K. Sikka, M. F. Modest, and J. R. Hellmannj, "High-Temperature, Normal Spectral Emittance of Silicon Carbide Based Materials," J. Thermophys. Heat Transf., vol. 8, no. 3, pp. 412-418, 1994.

[27] D. Especel and S. Matte, "Total emissivity measurements without use of an absolute reference," Infrared Phys., vol. 37, pp. 777-784, 1996.

[28] M. D. Drury, K. P. Perry, and T. Land, "Pyrometers for Surface Temperature Measurement," J. Iron Steel Inst., vol. 169, pp. 145-150, 1951.

[29] P. R. C. Goard, "Application of hemispherical surface pyrometers to the measurement of the emissivity of platinum (a low-emissivity material)," J. Sci. Instrum., vol. 43, pp. 256258, 1966.

[30] J. P. Millard and E. R. Streed, "A Comparison of Infrared-Emittance Measurements and Measurement Techniques,” Appl. Opt., vol. 8, no. 7, pp. 1485-1492, 1969. 
[31] K. E. Nelson and J. T. Bevans, "Errors of the Calorimetric Method of Total Emittance Measurement," in NASA SP-31 - Measurement of Thermal Properties of Solids, 1963, pp. $55-65$.

[32] R. E. Gaumer and J. V. Stewart, "Calorimetric determination of infrared emittance and the a/E ratio," in NASA SP-31 - Measurement of Thermal Properties of Solids, 1963, pp. 127133.

[33] G. D. Gordon and A. London, "Emittance measurements at satellite temperatures," in NASA SP-31 - Measurement of Thermal Properties of Solids, 1963, pp. 147-151.

[34] D. Giulietti, A. Gozzini, M. Lucchesi, and R. Stampacchia, "A calorimetric technique for measuring total emissivity of solid materials and coatings at low temperatures," J. Phys. D. Appl. Phys., vol. 12, pp. 2027-2036, 1979.

[35] H. Masuda, S. Sasaki, M. Higano, and H. Sasaki, "A Method for the Simultaneous Measurement of Total Hemispherical Emissivity and Specific Heat of Metals by the Transient Calorimetric Technique," Exp. Therm. Fluid Sci., pp. 218-225, 1991.

[36] R. Smalley and A. J. Sievers, "The total hemispherical emissivity of copper," J. Opt. Soc. Am., vol. 68, no. 11, pp. 1516-1518, 1978.

[37] K. G. Ramanathan and S. H. Yen, "High-temperature emissivities of copper, aluminum, and silver," J. Opt. Soc. Am., vol. 67, no. 1, p. 32, Jan. 1977.

[38] G. B. Smith and H. Willrath, "Calorimetric emissivities for solar-selective coatings on flat sheet," J. Phys. E., vol. 12, pp. 813-814, 1979.

[39] R. Sadler, L. Hemmerdinger, and I. Rando, "Emissometer - A device for measuring total hemispherical emittance," in NASA SP-31 - Measurement of Thermal Properties of Solids, 1963, pp. 217-223.

[40] H. Willrath and R. B. Gammon, "The Measurement of Optical Properties of Selective Surfaces Using a Solar Calorimeter," Sol. Energy, vol. 21, pp. 193-199, 1978.

[41] H. Willrath and G. B. Smith, "A New Transient Temperature Emissometer," Sol. Energy Mater., vol. 4, pp. 31-46, 1980.

[42] W. W. Beens, M. Sikkens, and J. L. Verster, "An emissometer with high accuracy for determination of the total hemispherical emittance of surfaces," J. Phys. E., vol. 13, pp. 873-876, 1980.

[43] H. B. Curtis, "Measurement of Emittance and Absorptance of Selected Materials between $280^{\circ}$ and $600^{\circ}$ K.," J. Spacecr. Rockets, vol. 3, no. 3, pp. 383-387, 1966. 
[44] G. L. Harding and B. Window, "Graded metal carbide solar selective surfaces coated onto glass tubes by a magnetron sputtering system," J. Vac. Sci. Technol., vol. 16, pp. 16-20, 1979.

[45] B. Window and G. Harding, "Thermal emissivity of copper," J. Opt. Soc. Am., vol. 71, no. 3, p. 354, Mar. 1981.

[46] A. I. Funia, "A multichamber calorimeter for high-temperature emittance studies," in NASA SP-31 - Measurement of Thermal Properties of Solids, 1963, pp. 317-327.

[47] D. L. McElroy and T. G. Kollie, "The total hemispherical emittance of platinum, columbium-1\%, zirconium, and polished and oxidized iron- 8 in the range $100^{\circ} \mathrm{C}$ to $1200^{\circ}$ C," in NASA SP-31 - Measurement of Thermal Properties of Solids, 1963, pp. 365379.

[48] T. W. Nyland, "Apparatus for the measurement of hemispherical emittance and solar absorptance from $270^{\circ} \mathrm{C}$ to $650^{\circ} \mathrm{C}$," in NASA SP-31 - Measurement of Thermal Properties of Solids, 1963, pp. 393-401.

[49] R. Brandt, C. Bird, and G. Neuer, "Emissivity reference paints for high temperature applications," Measurement, vol. 41, no. 7, pp. 731-736, 2008.

[50] A. J. Sievers, “Thermal radiation from metal surfaces," J. Opt. Soc. Am., vol. 68, no. 11, pp. 1505-1516, Nov. 1978.

[51] F. Cao, K. McEnaney, G. Chen, and Z. Ren, "A review of cermet-based spectrally selective solar absorbers,” Energy Environ. Sci., vol. 7, no. 5, p. 1615, 2014. 